\section{Modulus of Elasticity}

Jeffrey R. Keaton

Amec Foster Wheeler, Los Angeles, CA, USA

\section{Definition}

Modulus of elasticity $(E)$ is the name given to the slope of the stress-strain $\left(\sigma_{x}-\varepsilon_{x}\right)$ curve for a material subject to axial principal stress in the elastic range of the material. It is synonymous with Young's modulus, which also is represented by the symbol $E$.

\section{Cross-Reference}

> Young's Modulus 